\title{
The transition of the biosphere into the noösphere: forecast of Vernadsky and reality \\ ANDREW BYCHKOV
}

Lomonosov Moscow State University

Presenting Author: andrewbychkov@rambler.ru

The term "noösphere" was proposed in 1927 by the French mathematician and philosopher E. le Roy influenced by the famous lectures of Vernadsky at the Sorbonne University. In these lectures, Vernadsky presented the concept of the biosphere, which caused a lot of discussion. Today the theory of the biosphere is generally accepted in science. Vernadsky began to develop the theory of the noösphere mainly during the World War II, but he died before the Victory and did not complete his work. Vernadsky, analyzing the geological history of the Earth, argues that there is a transition of the biosphere to a new state to the noösphere under the influence of a new geological force, the scientific thought. Unfortunately, there is no complete and consistent interpretation of the essence of the noösphere in works of Vernadsky. In some papers, he wrote about the noösphere in the future tense, in others in the present, and sometimes associated the formation of the noösphere with the appearance of the first Homo or with the industrial production. He wrote about the formation of the noösphere on the Earth in unfinished work "Scientific Thought as a Planetary Phenomenon" (in Russian) and in English in the article "The Biosphere and the Noösphere" (American Scientist, Vol. 33, No. 1). Today, 75 years later, the influence of civilization on the biosphere is obvious and it is necessary to return to the main theses of Vernadsky on the theory of the noösphere. We must compare Vernadsky's predictions with such works of economists as "The Limits to Growth" (1972) by Dennis Meadows et al. and present-day development trends in terms of geochemistry. The ideas of the transition of the biosphere to a new era are already being discussed. In particular, the Anthropocene has been proposed as the new epoch of the anthropogenic impact on the global environment. The study of development trends shows that the transition occurs today and resembles a thermodynamic second-order phase transition. Perhaps many of unusual processes in society can be explained in terms of transition to noösphere. 